\title{
Marriage in Changing Family Pattern of Bangladesh: The Present Trends
}

\author{
Muhammad Samad \\ Social Welfare and Research Institute, University of Dhaka, Bangladesh \\ University of Information Technology \& Sciences (UITS), Bangladesh \\ *Corresponding Author: samadswidu@yahoo.com
}

\begin{abstract}
Family, the basic unit of society, all over the world has been undergoing many fundamental changes and profound transformation due to comprehensive socio-economic development and technological advancement. This paper is a humble attempt to examine the factors affecting changes in family pattern, age at marriage, practice of dowry and divorce in family life of Bangladesh. The major factors affecting changes are expansion of educational and employment opportunities, introduction of advanced technologies in production sectors, increased access to development services like micro-finance, health, education, and social awareness avenues, economic and political empowerment among the family members including legal measures for protecting women and children from negative consequences of dowry practice and divorce, in particular. Still, several problems emerged from the changed family pattern in Bangladesh that included break-down of joint family system, degradation of moral values, negligence toward the dependent and aged members, wide practice dowry and divorce, increase in new demands of the family members, development of self-centered attitude, and increased conflict in conjugal as well as family life. On the basis of above findings and discussions, some specific measures may be suggested as intervention strategies for solving the problems emerged from the changed family pattern in Bangladesh including the practice of dowry and divorce. These measures are: counseling by the trained social workers, legal literacy and social education relating to family-life, women empowerment, new employment creation, strengthening health care services at grassroots, proper enforcement of family, child and marriage related laws. The role of mass media should be encouraged in raising awareness among community people and government functionaries including the law enforcement agencies so that they should come forward to improve their life situation in accordance with the changes in family pattern of Bangladesh. Finally, in a changing society of Bangladesh, professionally skilled and trained social workers can greatly contribute to make all the social efforts and human service activities more effective and meaningful.
\end{abstract}

Keywords Changing Society, Family Pattern, Marriage, Dowry, Divorce, Development Service and Intervention Strategy

\section{Bangladesh: Economy, Society and Culture}

Bangladesh appeared on the world map as an independent and sovereign state in December 1971 following victory at the War of Liberation from March 25 to December 16, 1971. Bangladesh is among the most highly and densely populated countries in the world. The recent estimates of Bangladesh's population range from 150 to 160 million, make it the seventh most populous nation in the world. With a land area of 144,000 square kilometers $\left(55,600\right.$ sq. mile, ranked $\left.94^{\text {th }}\right)$ the population density is remarkable. The population is relatively young, with the 25 and under age group comprising $60 \%$ while $3 \%$ is 65 or older. The number of civilian labor force is 61 million. Life expectancy is 70.7 years (for males 69.9 years, for females 71.5 years) and current literacy rate is 62.3 percent (Ministry of Finance, 2015 ,p. xvii). As a result of continued domestic and international efforts to improve socio-economic condition, Bangladesh achieved the lower-middle income status in recent time. Its per capita income has reached USD 1324 in 2014-15 fiscal year (Bangladesh Bureau of Statistics, 2013; Ministry of Finance, 2015,p. xvii). The country has made significant progress in human development in the areas of literacy, gender parity in schooling and reduction of population growth. Obstacles to the country's growth include frequent cyclones and floods, inefficient state-owned enterprises, mismanaged port facilities, inefficient use of energy resources (e.g. natural gas), insufficient power supplies, slow implementation of economic reforms, political conflicts etc. Despite many hurdles, the country has achieved an average annual growth rate of $6.51 \%$ (Ministry of Finance, 2015,p. xvii).

The ethnic composition of Bangladesh is mosaic of mixed races with a dominant non-Aryan strain. More than 80 percent of its population lives in rural areas. The fertile lands and vast water bodies have made agriculture the major occupation and rice, vegetable and fish have become their main foods. The society of Bangladesh is cohesive and mostly characterized by joint family. They have respect and love for women, elders and children as well. Traditionally the parents, elderly and disable dependants are taken care of by the families of their sons or daughters or relatives. 
Although currently more than 90 percent of the country's populations are Muslims yet the customs and traditions in Bangladesh are varied and fascinating. In spite of rapid expansion of education and modern amenities, rural people and indigenous communities still retain an unconscious belief in animism in Bangladesh. However, Eid, Durga Puja, Buddha Poornima and Christmas are the main religious festivals of the Muslims, Hindus, Buddhists and Christians of the country respectively. The indigenous communities living in forests, hill tracts, plain lands and tea gardens have their own colorful festivities centering round different deities.

In ancient India (of which Bangladesh is culturally an integral part) there were sporadic as well as organized efforts to help the needy and victims of natural disasters. At one time, the advent of Islam brought about a renaissance among the relatively lower caste population in India under a conversion process. Islam institutionalized charity work through its various systems like zakat, fitra, baitulmal, etc. Thus, some forms of social welfare activities have evolved and have been practiced in Bangladesh like elsewhere in the world (Karim, 1996; Sarker, 1995). In regard to psycho-socio-economic problems, abuse of children and women, physical, mental and social disabilities, over population, acute poverty, unemployment, illiteracy and poor health are common in Bangladesh. The government agencies (GAs) and Non-Government Organizations (NGOs e.g. BRAC, Grameen Bank, Proshika, ASA, etc.) have been implementing various economic and social development programs through micro-finance, human development training, conscientization and advocacy to improve the life situation of the poor and disadvantaged segment of the population of the country (Samad, 2000).

\section{Background of the Study}

It is obvious today that family, the basic unit of society, all over the world has been undergoing many fundamental changes and profound transformation due to comprehensive socio-economic development and technological advancement. It is significant in this connection that both in developed and developing countries including Bangladesh, the average family size has decreased; young people are getting married at a later age; the average age of mothers at first birth has increased; infant mortality rates have declined and couples are choosing children fewer in number. The rate of divorce has increased accompanied by remarriage with many children living in a family with a step-parent. Significant number of both single-parent families and single-person households has emerged, including increasing number of older persons living alone. In many cases traditional agrarian life-styles based extended family is being replaced by the nuclear family. The whole process is simply considered as changes in families chiefly in terms of structure and role performance. Another important development in regard to education of girls and participation of women in formal labor force has markedly increased over the past half century. It has dramatically changed in the structure of family and its role performance in socio-economic life in particular. There is a general trend in developed countries among older persons toward living alone or only with their spouses, and recently there is growing preference for separate residence in some developing countries as well. While over 70 percent of older persons in developing regions are living with child or grandchild. In European countries, by contrast, the average is around 25 percent only. On the other hand, it is very relevant and important to say that HIV/AIDS pandemic affects families in a profound and tragic way. When a family member, particularly a parent becomes sick, weakened or dies, everyone in the family badly suffers and it affects family structure and functions of the poorest developing countries of Africa, in particular (United Nations, 2006). As a developing country Bangladesh has been experiencing almost similar situation in this regard.

The present paper is based on a recent study on changing family pattern in Bangladesh conducted under the fellowship grant of Social Science Research Council (SSRC) of the government of Bangladesh. In Bangladesh, although some studies were undertaken by Chowdhury $(1978 ; 1987)$, Karim (1996), Khan (1969) and Hara (1972) as a whole on changing pattern of the rural society as well family, most of them are more or less descriptive in nature. In these studies, the researchers have collected and analyzed socio-demographic data mostly about family in terms of family size, age, education, occupation, income of family etc. for understanding changing family pattern and its impacts on socio-economic life situation. However, as we surveyed, there has not been a considerable study in the context of factors affecting changes in family pattern of Bangladesh and development priorities in terms of opportunities and challenges of the changing families, which needed to be carefully conducted.

In Bangladesh, the government, NGOs, UN Agencies and civil societies are active in advocating both for policies needed to enhance family well-being and welfare through providing essential services such as education, health care, shelter, employment, recreational activities for their members. In this connection this paper is a humble attempt to examine the factors affecting changes in family pattern, age at marriage, dowry and divorce in family life of the country.

\section{Methodology}

Both the qualitative and quantitative data were collected in view of objectives set-out for the study. To conduct the present study conveniently, 10 villages, five from Trishal upazilla/sub-district under Mymmensingh district and five villages from Tarash upazilla/ sub-district of Sirajgonj district in Bangladesh were selected for data collection. A detailed interview schedule and a checklist were prepared for 
conducting the field survey and face to face interview technique was used for data collection. A total of 151 respondents were interviewed through the detailed interview schedule having 65 open and structured questions. Besides, for enriching study findings, relevant data was also collected through discussions with members of the families, community leaders, and development workers involved in various family welfare activities. A Study Team comprising five members including a principal researcher worked for data collection. The principal researcher participated at all phases of data collection including the FGDs, in the fields.

It is significant to note that the present study on changing family pattern is based upon two generations i.e. present and earlier generation families in Bangladesh. The identifying point/demarcation line of present and earlier generation was drawn mainly on the basis of period of time. In this respect, the patterns of Bangladeshi families before and after 1980s were considered as earlier and present generations for the study respectively. Therefore, the data were collected purposefully from the age-group of 35 to above 65 years so that they could provide information from their observation, experience and memories regarding changing pattern of their families during two generations, in particular.

The logic behind above mentioned period as identifying point includes, after the independence of the country through the War of Liberation in 1971, the Bangladesh experienced several political turmoil including military rules, re-emergence of communal attitude in the society, job/employment searching in abroad particularly in the middle-east, the USA and UK that played important roles in changing socio-political, economic as well as family-life of the people of the country. Introduction of advance technology such as computer, mobile phones, fax, modern transportation, engine-boat, growing use of ready-made garment sector, non-farm employment generation and rapid modernization of agriculture as well as migration of rural population to urban areas made commendable changes in the family pattern of Bangladesh. Likewise, the politico-economic turmoil in the eighties including glasnost-perestroika of the then Soviet Union, down-fall of socialism in east-Europe and capitalist move in terms of private ownership and free-market economy within one-party system in China played important roles in changing family pattern all over the world, in particular (Stockwell and Youyi, 2004).

\section{Changing Family Pattern in Bangladesh}

This section deals with the changes in family pattern and factors held responsible for affecting the changes in brief. With regard to changes in family-size, type and likings of family, the study findings revealed that the family size was larger (8.26) in earlier generation families than the present ones (5.57) which is a clear indication of structural change in the family pattern of Bangladesh. On the other hand, it is very significant that 62.25 percent respondents were in favor of joint family mainly for mutual love, sympathy and cooperation of members, financial solvency in family through collective income and cost-effective family management, building savings capability and insuring the security of dependent family members, etc. However, the people living in urban areas prefer single family in Bangladesh.

The major factors affecting changes in the family pattern of Bangladesh were expansion of educational and employment opportunities, introduction of advanced technologies in agriculture and other production sectors, increased access to development services like self-employment through micro-finance, health, education, and social awareness avenues, economic and political empowerment among the family members in the country. The findings indicated that modernization and urbanization are connected with small family structure.

It is evident from the findings of the study that the roles and functions of family have changed over time in accordance with the changing pattern of families in Bangladesh. In this respect, almost hundred percent respondents opine that changed family roles have caused increased employment opportunities for the family members, participation in decision-making, more enrolment in educational institutions, increased awareness about health and nutrition etc.

In respect of changing family functions, the causes identified were expansion of educational activities, increased access to employment, impact of science and technology, industrialization and urbanization, increased social awareness and expectation of self-esteem among family members, etc. The study findings further revealed that because of changes in the functions of family, some impacts and consequences were found in family life of the people of Bangladesh. The positive impacts included economic prosperity and security, change in food habit, increased participation of the women in education, employment and decision-making process, peace and happiness among family members. The consequences were lack of care of the children, complexity in family management, increased insecurity of the dependent family members including the physically and intellectually challenged persons. However, it is observed from the findings that due to expansion of education, motivational role of mass media, religious values and beliefs, government and NGO services, taking care of the aged and depended family members has increased

One of the important objectives of the present study was to see involvement of the people of the study area with the program activities and services rendered by the government agencies (GAs) and NGOs working in Bangladesh. In this respect, most of them were found involved in the activities of the government nation building departments and national, regional and local NGOs. It is further evident from the study findings that the status of women has upgraded among the women members of present generation families in 
comparison with earlier ones. However, the factors affecting the up gradation of women status in Bangladeshi families were identified included participation in family decision-making process, involvement in employment/self employment, increased enrolment/participation in educational activities, participation in development programs of the government and NGOs, increased awareness about women rights, development of women leadership, positive change in the mindset of their male counterparts, decreased belief in superstition, role of mass media, impact of state policy and law in favor of the women, and participation in political and social activities which actually empowered the women of present generation compared to the earlier ones in Bangladesh.

On the contrary, several problems emerged from the changing family roles in Bangladesh that included break-down of joint family system, degradation of moral values, negligence toward the dependent and aged members, decline in family tie, less time for child rearing, increase in cost of family maintenance, increase in new demands of the family members and proneness to self-centered attitude, improper socialization of children and easy access to western culture, decrease in influence of religion, and increased conflict in conjugal and family life. The study findings expressed that modernization is positively as well as negatively related with family structure.

However, opinion of the respondents was sought regarding the means for intervention strategies of solving the problems emerged from changed family roles as well as changing family pattern in Bangladesh. In this connection, a good number of measures suggested by the respondents include i) providing counseling/education relating to family life, ii) expanding educational facilities, iii) strengthening women development activities, iv) creating employment opportunities, v) eradicating corruption from various service sectors, iv) expanding program for ensuring health services at grassroots level, vii) providing credit to the poor, viii) proper application of family and marriage related laws along with legal literacy, ix) ensuring proper distribution of land and other assets among family members and so on.

\section{Marriage in Changing Family Pattern}

Marriage is a social union or legal contract generally between a man and a woman that creates kinship. It is an institution in which interpersonal relationships, usually intimate and sexual, are acknowledged in a variety of ways, depending on the culture or subculture in which it is found. Such a union often formalized via a wedding ceremony. In Bangladesh, marriage is a civil contract between two adult persons of opposite sexes for union, procreation and legalizing children. The present study examined some particular aspects of marriage such as age at marriage, opinions of the marriageable family member, dowry and divorce in changing family pattern.

\section{Age at Marriage}

With regard to age at marriage of the present and earlier generation family members it is revealed from the study that average ages at marriage of the present and earlier generation families were found to be about 22 years and slightly more than 19 years respectively. While the average ages at marriage of the male and female members of present generation families were found about 24 years and 20.10 years which is more than the mean age at first marriage in 2007 for male (23.40 years) and female (18.40 years) in Bangladesh (Ministry of Finance, 2008). The average ages of the earlier generation family members were about 22 years and 16.33 years for male and female in this regard respectively. It does indicate that the average age at marriage of the earlier generation family members (19 years) was less than that of the present ones (22 years). It is most important to note that the age at marriage of the female members was found less than the age of male members at marriage in both generations of families. However, it is significant that according to 83.44 percent respondents, average ages at marriage of the present generation families have been increasing while a small number of respondents (16.56 percent) opined that the age at marriage is also being decreased in some families of Bangladesh. In this connection, most of the respondents referred to awareness about reproductive health, awareness about consequences of early marriage, impact and implication of marriage related laws, expansion of educational programs activities and increased scope of education, employment and empowerment of women, decrease in socio- religious superstition and prejudice and desire for self-reliance as significant factors behind increasing age at marriage. In this respect, the other factors include increased enrolment in higher education and desire for happiness in conjugal life, role of local leadership and Union Parishad, government and NGOs' initiatives i. e. awareness campaigns, workshops and trainings about implication of birth registration. Besides, some negative factors were found responsible for increase in/of age at marriage that included poverty, scarcity of expected bridegroom for the marriageable daughters and inability to satisfy the demand of dowry etc. On the contrary, 16.56 percent respondents opined that in some cases the age at marriage is being decreased among the rural people in Bangladesh. According to them, the reasons behind decreasing age at marriage included lack of social security for women, lack of awareness, involvement in income earning activities, prevailing dowry systems, rapid physical growth and long standing practice and tradition of rural people, negative impact of giving scope for marriage by likings, lack of application of marriage related laws and scarcity of expected bridegroom, and protecting family prestige and status.

It is worth mentioning here that because of birth registration, the marriage registrar cannot hide age of the marriageable population in Bangladesh and it is one of significant precautions to protect early marriage in the 
country. It may also be said that because of involvement in income earning activities of the unmarried rural boys, in particular, the parents arrange marriage for them which actually add the number of married population at tender age. And, the situation is reverse for the unmarried young population in the urban areas because they become more ambitious and careful for their career and take time to get married.

\section{Opinion of the Marriageable Family Members}

With regard to the importance of opinion, 86.09 percent respondents emphasize on the importance of taking opinion of the marriageable family members, about 14 percent respondents were not in favor of the issue. However, the factors causing importance in regard to taking opinion of the marriageable family members at the time of their marriage identified included expansion of educational activities, giving importance on liking of the marriageable family members, expectation of peace and happiness in conjugal life, income earning activities/professional affiliation, increasing individual liberty and self-esteem, ensuring future security of parents, role of mass media, equal participation of family members in decision-making process, awareness about laws relating to marriage and impact of modernization, women empowerment, protecting family prestige and status, and preventing family disorganization.

On the other hand, out of the total (151) sample, only 21 respondents did not emphasize on the importance of taking opinion from the marriageable family members at their marriage. In this regard, all of them considered the guardian's decision as perfect for marriage of the family members. Besides, protecting family prestige and status, not giving priority to emotions, lack of awareness about the rights of family members regarding marriage, wrong decision of the marriageable members, social insecurity, religious and social superstition, dominance of patriarchy, rejecting social recognition of love-affairs, and expectation of family happiness were identified as reasons for not giving importance on taking opinion from the marriageable family members.

\section{Dowry Practice and Divorce in Changing Family Pattern}

Both dowry and divorce are integral phenomena of marriage. As a custom, dowry has been practicing since longtime by the people belonging to all religions in Bangladesh. Generally, dowry means any property or valuable security given or agreed to be given at the time of marriage mostly by the parents of bride or bridegroom. A common understanding prevails that dowry originated and was adopted from the tradition of giving wedding gifts to the groom among the higher Hindu castes in the region (Amin and Cain, 1997; Goody and Tambiah, 1973; Jaggie, 2001) Over time, among the Muslim, there was a shift from the earlier practice of bride wealth (pon) which favored the bride and her family to the new practice of 'demand dowry' that is given to the groom and his family as forced gift-giving. Thus, it is now established as unrecognized social custom and marriage is hardly possible without dowry in Bangladesh.

According to the present study, supported by Nasrin (2011), the major reasons behind increasing practice of dowry in Bangladesh are economic gain, achieving social recognition and status, maintenance of family reputation and prestige, ensuring daughters' welfare and happiness, freedom of daughter from violence, ill-treatment and verbal abuse by in-law family, enhancing husband's command over in-laws, bargaining power in family decisions, making any imperfection of bride or older girl acceptable, poor law enforcement and lengthy court procedures as well as wrong perception regarding dowry. For example, professionals such as doctors, engineers, lawyers, police, and army officers expect a large dowry as a ticket to high social status and wealth. This reflects the fact that dowry is viewed as the direct exchange of status for wealth. That is higher the status of groom higher the exchange of dowry. Besides, the groom's family takes advantage of the situation when the parents of a bride are willing to make a dowry payment to marry off their daughter to an educated man with a good job. It indicates that higher education and good job of the groom connected with getting dowry. On the other hand, non-fulfillment of dowry results in incidence of physical and verbal abuse of wives, which is a common phenomenon in Bangladesh while it puts the poor women in a helpless and vulnerable position violating their human rights and dignity (Suran, Amin, Huq and Chowdhury, 2004; Bangladesh National Women Lawyers' Association, 2004). Dowry demands thus continue to undermine gender equality, enforcing culturally accepted forms of discrimination against them.

Generally, in societies that allow the dissolution of a marriage this is known as divorce. It is a legal way of terminating the marriage having significance consequence. In Bangladesh, divorce is being practiced mostly among the Muslim. It is revealed from the present as well as other studies that divorce has been taking place in the country mainly because of severe poverty, illiteracy or lack of education, early marriage, love match, demand for dowry, absence of prior understanding between bride-groom and their families and long-standing practice of domination by husband and in-laws. Besides, mental torture e.g. threats of second marriage, divorce, inflicting violence and demand for dowry as well as physical tortures on married women are expediting divorce in Bangladesh.

In general, the consequences of divorce are more severe for women than men. In most cases, the poor women are to take the responsibility of children and suffer in many ways including in meeting basic human needs. Moreover, divorce 
results in emotional problems such as maladjustment with surroundings, trauma, social indignation/stigma for the divorcees and their families as well (Ahmed, 2007). Nevertheless, in insignificant cases, divorce is considered as growing awareness among women about human rights and motivation for raising voice against family violence and discrimination in Bangladesh.

However, frequent practice of dowry and divorce is essentially not conducive for harmonious and happy family life as well as healthy society. Reviewing the detrimental consequences of dowry and divorce, the Government of Bangladesh has initiated some legal measures through enacting the Dowry Prohibition Act (1980), Women and Children Repression Act, 2000, Acid Crime Prevention Act, 2002 and so on. These laws provide trials and various punishments to the offenders but in many cases law does not work accordingly because of lengthy court procedures and weak enforcement in reality. Initiatives like awareness raising, legal aid, publicity of adverse effects and social campaigns against dowry as well as divorce have been undertaken both by government agencies and non governmental organizations (NGOs).

\section{Suggested Intervention Strategies}

On the basis of the study findings and discussions, some specific measures may be suggested as intervention strategies for solving the problems emerged from the changing family pattern in Bangladesh including the practice of dowry and divorce. i) Counseling service should be provided by the trained social workers. ii) Legal literacy and social education relating to family-life should be strengthened. iii) Special emphasis should be given on women empowerment insuring their participation in development activities in terms of training, micro-credit, trading and marketing by using public places. iv) For better livelihoods of the people, poverty reduction programs as well as new employment creation should be strengthened. v) Implementation of health care services should be strengthened at grass-root level. vi) Initiative should be taken to ensure proper enforcement of family, child and marriage related laws. vii) Mass media can play important role in raising awareness among community people and government nation building functionaries including law enforcement agencies of the country so that the women as well as their male counterparts should come forward to improve their life situation in accordance with the changes in family pattern of Bangladesh.

Finally, although the professional practice of social work has been started in 1957 through implementation of the Urban Community Development Project in the capital city of Bangladesh, still social work is not professionally recognized in the country. It is a great misfortune that most of the government agencies (GAs) and NGOs involved in social development services are unaware of social work philosophy. Hence, awareness and advocacy campaign is needed for applying social work knowledge, and skills for enriching human services and sustainable development for the people of Asia-Pacific region. In this connection, in a changing society of Bangladesh, professionally skilled and trained social workers can greatly contribute to make all the social efforts and human service activities more effective and meaningful.

\section{REFERENCES}

Ahmed, N. (2007). Divorce Women in Bangladesh. Dhaka. A. H. Development Publishing House..

Amin, S. and Cain, M. (1997). 'The Rise of Dowry in Bangladesh'. In G. W. Jones, J. C. Caldwell, R. M. Douglas and R. M. D’Souza (eds.), The Continuing Demographic Transition. Oxford: Oxford University Press.

Bangladesh Bureau of Statistics (2007). Statistical Yearbook of Bangladesh 2005. Dhaka: Bangladesh Bureau of Statistics, Planning Division, Ministry of Planning, Government of the People's Republic of Bangladesh.

BBS (2010). Monitoring Survey on Basic Needs and Opportunities: 2009. Dhaka: Bangladesh Bureau of Statistics, Planning Division, Ministry of Planning, Government of the People's Republic of Bangladesh.

BBS (2013). Monitoring the Situation of Vital Statistics. Dhaka: Bangladesh Bureau of Statistics, Planning Division, Ministry of Planning, Government of the People's Republic of Bangladesh.

Bangladesh National Women Lawyers' Association (BNWLA) (2004). Violence Against Women in Bangladesh. Dhaka.: BNWLA..

Chowdhury, A. (1978). A Bangladesh Village: A Study of Social Stratification, Dhaka: Centre for Social Studies (CSS), University of Dhaka.

Chowdhury, A. (1987) Studies in Socio-cultural Change in Rural Villages in Bangladesh. No. 5. Tokyo, Institute for the Study of Languages and Cultures of Asia and Africa.

Goody, J. and Tambiah, S. J. (1973). Bride Wealth and Dowry. London: Cambridge University Press..

Hara, T. (1972). Studies in Socio-cultural Change in Rural Villages in Bangladesh, No. 1. Tokyo, Institute for the Study of Languages and Cultures of Asia and Africa.

Jaggi, T. (2001). The Economics of Dowry: Causes and Effects of an Indian Tradition. Cambridge, Mass Harvard University, University Avenue Undergraduate Journal of Economics (UAUJE). Retrived on 25.11.2005 from

http://www.econ.ilstu.edu/uauje/PDF's/issue2001/Jaggi.pdf .

Khan, S.H. (1969). Changing Urban Family Pattern. Dacca: College of Social Welfare and Research Centre, Dacca University.

Karim, A.K.N., (1996). Changing Society in India, Pakistan and Bangladesh. Dhaka: Nawroze Kitabistan.

Ministry of Finance (2008). Bangladesh Economic Review 2007. Dhaka: Economic Adviser's Wing, Finance Division, Ministry of Finance, Government of the People's Republic of Bangladesh. 
Ministry of Finance (2015). Bangladesh Economic Review 2015 (in Bangla). Dhaka: Economic Adviser's Wing, Finance Division, Ministry of Finance, Government of the People's Republic of Bangladesh.

Nasrin, S. (2011). 'Crime or Custom? Motivations Behind Dowry Practice in Rural Bangladesh'. Indian Journal of Gender Studies. Volume 18, Number 1, New Delhi. Sage Publications.

Samad, M. (2000). Participation of the Rural Poor in Government and NGO Programs. Dhaka: Mawla Brothers.

Sarker, A. H. and Ahmadullah, A. K. (1995). "Bangladesh" in International Handbook on Social Work Education edited by
Tomas D. Watts et al.. London: Greenwood Press..

Suran, L., Amin, S., Huq, L. and Chowdury, K. (2004). Does Dowry Improve Life for Brides? A Test of the Bequest Theory of Dowry in Rural Bangladesh. New York: Policy Research Division, Population Council.

United Nations (2006). Changing Families: Challenges and Opportunities (Theme for the observance of International Day of Families 15 May (2006), Resolution 47/237 of 20 September 1993 of the UN Genera Assembly. New York. UN. 